\title{
Современное образование
}

УДК 65.012.2

DOI dx.doi.org/10.24866/VVSU/2073-3984/2017-3/164-178

\author{
А.А. Гресько ${ }^{1}$ \\ К.С. Солодухин ${ }^{2}$ \\ Владивостокский государственный университет экономики и сервиса \\ Владивосток. Россия
}

\section{Выбор смешанных типов стратегий взаимодействия университета с иностранными студентами на основе нечеткой многопериодной модели*}

\begin{abstract}
Целью работы являются разработка и апробация метода выбора стратегий взаимодействия вуза с группой заинтересованных сторон «Иностранные студенты» на основе нечеткой многопериодной модели выбора смешанных типов стратегий взаимодействия организации со стейкхолдерами. Показаны преимущества использования нечеткой модели по сравнению с ранее предложенными. Выделение иностранных студентов в качестве отдельной релевантной группы заинтересованных сторон связано со значительным ростом ее значимости в функционировании большинства отечественных вузов. Метод описывается на примере Владивостокского государственного университета экономики и сервиса (ВГУЭС), для которого, учитывая особенности приграничного территориального расположения, ведение международной деятельности является неотъемлемой составляющей развития. Выбор ВГУЭС для апробации метода связан также с существенным превышением значений большинства показателей мониторинга эффективности, относящихся к международной деятельности, медианных значений показателей государственных и муниципальных вузов страны. Описан ресурсный обмен группы стейкхолдеров «Иностранные студенты» $\mathrm{C}$ региональным университетом, и показана его специфичность. Выделены три возможных сценария развития отношений университета с группой заинтересованных сторон, в основе которых лежат различные изменения структуры спроса стейкхолдеров. Рассчитана целесообразность применения каждого из пяти «чистых» типов стратегий взаимодействия по всем трем сценариям с использованием расстояния Хемминга как меры близости соответствующих нечетких чисел. Предложены смешанные стратегии взаимодействия вуза с группой стейкхолдеров. Показаны их преимущества по сравнению с возможными чистыми стратегиями. Определены «узкие» места в системе взаимодействия университета с иностранными студентами.
\end{abstract}

Ключевые слова и словосочетания: группы стейкхолдеров, стратегии взаимодействия, нечеткая модель, многопериодная модель, смешанные стратегии.

* Работа выполнена при поддержке гранта Президента Российской Федерации МК6656.2016.6.

\footnotetext{
${ }^{1}$ Гресько Александр Александрович - канд. экон. наук, доцент кафедры математики и моделирования; e-mail: gresko_al@mail.ru.

2 Солодухин Константин Сергеевич - д-р экон. наук, профессор кафедры математики и моделирования; e-mail: k.solodukhin@mail.ru.
} 
A.A. Gresko ${ }^{1}$

K.S. Solodukhin²

Vladivostok State University of Economics and Service

Vladivostok. Russia

\title{
Selecting mixed types of university engagement strategies with foreign student based on fuzzy multi-period model
}

\begin{abstract}
The aim of the work is to develop and approbate the method of selecting mixed types of university engagement strategies with foreign students based on fuzzy multi-period model for selecting mixed types of stakeholder engagement strategies of the company. The advantages of using the fuzzy model in comparison with the previously proposed ones are shown. The selection of foreign students as a separate relevant stakeholder group associated with a significant increase in its importance in the functioning of most national universities. The method is described on the example of Vladivostok State University of Economics and Service. International activity is an integral part of the University's development, taking into account the peculiarities of cross-border territorial location. The specificity of the resource exchange of the University with foreign students is shown. Three possible scenarios for the development of relations between the University and the stakeholder group are described. Mixed strategies for interaction between the University and the stakeholder group are proposed. Their advantages are shown in comparison with pure strategies. "Bottlenecks" in the system of interaction of the University with foreign students are defined.
\end{abstract}

Keywords: stakeholder groups, engagement strategies, fuzzy model, multi-period model, mixed strategies.

Одним из наиболее популярных подходов к разработке стратегий вузов является использование концепции заинтересованных сторон (стейкхолдерской теории фирмы) [11]. Современный университет представляет собой яркий пример организации, условием существования которой является способность устанавливать и поддерживать отношения с широким кругом заинтересованных сторон (стейкхолдеров). Такие организации были названы нами «стейкхолдер-организации». В свою очередь, была предложена концепция вуза как стейкхолдер-организации [15].

Количество выделяемых стейкхолдеров университетов различается у разных авторов. Например, у Е.А. Князева и Н.В. Дрантусовой их четыре [9], в работах Л.А. Малышевой их пять [11], в наших работах выделялось шесть релевантных групп заинтересованных сторон [4; 15]. Иностранные студенты обычно не выделялись в качестве отдельной группы, что было связано с их относительно небольшой ролью в функционировании большинства отечественных вузов. Однако в последние годы значение международной деятельности университетов существенно возросло. Повышенное внимание этому направлению уделяет Министерство образования и науки РФ.

\footnotetext{
${ }^{1}$ Gresko Aleksandr Aleksandrovich - Candidate of Economical Sciences, Docent of Mathematics and Modeling Department; e-mail: gresko_al@mail.ru.

${ }^{2}$ Solodukhin Konstantin Sergeevich - Doctor of Economical Sciences, Professor of Mathematics and Modeling Department, Head of Strategic Planning Lab; e-mail: k.solodukhin@mail.ru
} 
Заинтересованность вузов в привлечении иностранных студентов связана как с экономическими (рост доходов, рост учебной нагрузки), так и с социальными факторами (формирование поликультурной образовательной среды, мотивация к развитию программ на иностранных языках, воспитание толерантности), а также с определенными имиджевыми преимуществами, поскольку значительная доля иностранных студентов является признаком (и фактором) привлекательности вуза в мировом, национальном и региональном масштабах. Кроме того, вузы получают возможность выбирать лучших выпускников школ со всего мира, добиваясь таким образом улучшения качества образования [1].

Выделение иностранных студентов в качестве отдельной релевантной группы заинтересованных сторон обусловлено не только повышением их роли в деятельности университетов. Необходимо отметить и специфичность ресурсного обмена между этой группой и вузом.

Обучение иностранных студентов вносит определенную специфику в деятельность каждого вуза. Мера этой специфичности определяется содержанием обучения, организационно-методическими и ресурсными особенностями, необходимостью социально-культурной и бытовой поддержки. Иностранные студенты по своему статусу и уровню своей жизни в российском университете существенно отличаются от российских студентов, так как имеют другие личностные и образовательные потребности. Они приезжают в российские университеты с образовательной базой и ожиданиями, обусловленными образовательно-воспитательными системами своих стран [10].

Выбор набора стратегий взаимодействия с каждым стейкхолдером обусловливается стремлением организации к долгосрочной сбалансированности отношений со всеми ее стейкхолдерами, для чего в краткосрочном периоде организация может осознанно допускать нарушение баланса отношений с любой отдельной группой заинтересованных сторон, а именно удовлетворять интересы одних стейкхолдеров за счет других (перераспределяя созданную организацией как системой заинтересованных сторон ренту). В долгосрочном периоде преследование интересов одного из стейкхолдеров в ущерб остальным классам стейкхолдеров может привести к крайне негативным последствиям (такие последствия подробно описаны в работе [6]). Все это в полной мере относится к группе заинтересованных сторон «Иностранные студенты», несмотря на ее растущую значимость.

Целью данного исследования является разработка и апробация метода выбора стратегий взаимодействия вуза с группой заинтересованных сторон «Иностранные студенты» на основе нечеткой многопериодной модели выбора смешанных типов стратегий взаимодействия организации со стейкхолдерами.

Выбор стратегии взаимодействия организации со стейкхолдером определяется характеристиками сложившихся между ними отношений, связанных так или иначе с ресурсным обменом между ними. Однако, зачастую, упускается из внимания тот факт, что компания и стейкхолдеры в реальности обмениваются пучками ресурсов. При этом для каждой ресурсной компоненты, входящей в пучок, соответствующие характеристики отношений (зависимость, удовлетворенность, ожидания, желание 
изменений) могут существенно отличаться. В этой связи может возникнуть ситуация, при которой в отношении одного и того же стейкхолдера по разным наборам ресурсов организации следует придерживаться стратегий разных типов. Тем самым возникает необходимость формирования смешанных стратегий из стратегий базовых типов (удовлетворение запросов, защита, воздействие, сотрудничество, сдержанность).

Отношения между организацией и стейкхолдерами изменяются с течением времени. Характеристики отношений (зависимость, желание изменений) могут ослабевать или усиливаться, причем, не всегда монотонно. В этой связи возникает необходимость в использовании многопериодных моделей, позволяющих выбирать наиболее целесообразные типы стратегий взаимодействия компании с каждой группой стейкхолдеров.

Ранее авторами были разработаны такие многопериодные модели двух типов. Во-первых, многопериодные модели, позволяющие выбирать наиболее целесообразные типы стратегий взаимодействия компании с каждой группой стейкхолдеров [5]. Во-вторых, многопериодные модели выбора смешанных типов стратегий взаимодействия организации со стейкхолдерами [2; 3].

В данной работе описана нечеткая многопериодная модель выбора смешанных типов стратегий взаимодействия организации со стейкхолдерами. Использование нечетко-множественных инструментов связано с тем, что обычно выбор стратегий осуществляется в условиях высокой неопределенности, недостатка релевантной информации, носящей невероятностный характер (при одновременном огромном объеме неоднозначной информации, которую необходимо учитывать при принятии решений). Кроме того, измерение характеристик отношений в лингвистических шкалах существенно облегчает работу экспертов и повышает точность их оценок и прогнозов.

Продемонстрируем использование модели на примере Владивостокского государственного университета экономики и сервиса (ВГУЭС) и его группы стейкхолдеров «Иностранные студенты».

Учитывая особенности приграничного территориального расположения ВГУЭС, ведение международной деятельности является неотъемлемой составляющей в функционировании и развитии университета. По состоянию на 1 октября 2016 г. во ВГУЭС обучались 327 иностранных студентов, из них 250 из дальнего зарубежья (в первую очередь, из стран АТР: Китай, Лаос, Республика Корея, Япония, Вьетнам). Значение показателя мониторинга эффективности деятельности образовательных организаций высшего образования Е 3.1 «Удельный вес численности иностранных студентов (кроме стран СНГ), обучающихся программам бакалавриата, специалитета, магистратуры, в общей численности студентов (приведенный контингент)» $(5,02 \%)$ намного превышает медианные значения показателей государственных и муниципальных вузов России. Постоянно растет объем средств от образовательной деятельности, полученных ВГУЭС от иностранных граждан и иностранных юридических лиц. По данному показателю (41 985,5 тыс. руб.) ВГУЭС также значительно превышает медианные значения. Более того, такая 
ситуация (существенное превышение медианных значений показателей государственных и муниципальных вузов) наблюдается для 9 показателей международной деятельности из 13. Если же рассматривать медианные значения показателей вузов региона, то лишь один показатель ВГУЭС имеет значение ниже. В целом значение обобщенного показателя Е.3 «Международная деятельность» намного превышает установленное Министерством образования и науки РФ пороговое значение $(6,29$, при пороговом значении 1). При этом данный показатель показывает наибольшую положительную динамику из всех восьми основных показателей эффективности деятельности вуза.

Большое количество иностранных студентов не только говорит о высоком уровне образовательных программ и развитой инфраструктуре вуза, но и способствует научной и образовательной интеграции Дальнего Востока России в АзиатскоТихоокеанский регион и усилению влияния русского языка и культуры. Развитая международная деятельность, в том числе и наличие иностранных студентов, повышает привлекательность вуза и на внутреннем рынке [8].

Важно понимать, какие именно иностранные студенты обучаются во ВГУЭС и других региональных университетах. Если говорить о китайских студентах (а таких во ВГУЭС большинство), то самые лучшие выпускники школ пытаются поступить в национальные университеты, значительно продвинувшиеся в международных рейтингах вузов. Следующая группа абитуриентов ориентирована на англоязычные образовательные программы. При этом руководством КНР не поощряется обучение на таких программах не в англоязычных странах. В этой связи англоязычные программы, предлагаемые российскими вузами, оказываются невостребованными у китайских студентов. Третья группа абитуриентов поступает в ведущие университеты центральной части России. И, наконец, четвертая группа абитуриентов с более низким уровнем платежеспособности предпочитает поступать на русскоязычные программы в региональные российские университеты, такие, как ВГУЭС.

Опишем ресурсный обмен этой группы иностранных студентов с региональным университетом.

Университет получает от иностранных студентов следующие ресурсы:

1. Оплата образовательных услуг. Здесь важно отметить возрастающую значимость доходов региональных вузов от иностранных студентов в условиях значительного сокращения государственного финансирования (в том числе, существенного снижения контрольных цифр приема российских студентов). Цена образовательных программ для иностранных студентов более чувствительна, чем для российских. При этом ослабление рубля по отношению к мировым валютам повышает привлекательность российских русскоязычных образовательных программ не только за счет их стоимости, но и удешевления пребывания в стране.

2. Имидж. Иностранные студенты университета формируют имидж вуза в своей стране. Они делятся информацией со своими друзьями, знакомыми об уровне обучения, квалификации преподавателей, современности МТБ. Устраиваясь на работу после окончания университета, они формируют имидж вуза в бизнес-среде. 
Гресько А.А., Солодухин К.С. Выбор смешанных типов стратегий взаимодействия...

3. Выполнение показателей мониторинга Министерства образования и науки России, относящихся к международной деятельности.

Иностранные студенты получают от университета следующие ресурсы:

1. Документы, подтверждающие факт успешного окончания образовательных программ (дипломы, сертификаты). Здесь важно отметить меньшую чувствительность к бренду вуза со стороны иностранных студентов по сравнению с российскими.

2. Технологии преподавания. Образовательный процесс обучения иностранных студентов значительно отличается от обучения российских студентов. Для обучения иностранных студентов необходима разработка специализированных технологий и методик преподавания, обеспечивающих получение современных и востребованных знаний, формирование профессиональных компетенций. Развитие методологии обучения, использование в образовательном процессе инфокоммуникационных технологий также способны ускорить подъем уровня владения русским языком. Для методик нового поколения характерно углубленное исследование речевого общения как формы взаимодействия людей посредством языка.

3. Возможность реализации в культуре и спорте. Возможность реализации в спорте, творчестве, знакомства окружающих с культурой своей страны очень важна для иностранных студентов.

4. Комфортные условия проживания. Чтобы университет привлекал иностранных студентов, очень важно не только качество образовательных программ, но и наличие развитой инфраструктуры - общежития, спортзалы, столовые, библиотеки, информационные ресурсы. Для иностранных студентов комфортные и безопасные условия проживания - норма [8]. При этом играет большую роль, обособленно ли проживают студенты каждой страны или вперемешку со студентами других стран.

5. Система адаптации студентов в вузе, помощь в бытовых и жизненных ситуациях. Интернационализация современного высшего образования, продвижение России на международный рынок образовательных услуг актуализируют проблему приспособления иностранных студентов к образовательному пространству и адаптации к новой социокультурной среде, представленной новым социумом, городом и теми культурно-детерминированными реалиями, с которыми они сталкиваются в ином сообществе [10]. Процесс адаптации - сложный процесс, формирующий способности иностранного студента не только развиваться в области коммуникативного общения, изучения методики познания иностранного языка, но и успешно взаимодействовать в формировании новых качеств личности, приобретении новых ценностей, осмыслении значимости будущей профессии. Успешная и быстрая адаптация помогает быстро включиться в учебный процесс и способствует повышению качества подготовки студентов в вузе [12]. Адаптация иностранных студентов включает в себя их вовлечение в общеуниверситетские и городские мероприятия, приглашение на фестивали, выставки, концерты, а также организацию для них экскурсий и праздников [8].

6. Коммуникативная площадка для установления личных деловых контактов. Преимущество международного образования состоит не только в приобретении 
знаний иностранных языков, но и в установлении личных деловых контактов с коллегами из разных стран, а, значит, повышении конкурентоспособности при трудоустройстве [8].

Анализ взаимодействия университета с иностранными студентами базируется на следующих сценариях развития отношений.

Сценарий 1. В университете продолжается положительная динамика роста количества иностранных студентов, вызванная благоприятной экономической ситуацией и усилиями университета по увеличению контингента иностранных студентов. При этом количество востребованных иностранцами направлений подготовки существенно не меняется.

Сценарий 2. В рамках второго сценария предполагается рост спроса иностранных студентов на новые направления подготовки. В свою очередь это приведет к более быстрому темпу роста численности иностранных студентов, чем в первом сценарии.

Сценарий 3. В рамках третьего сценария предполагается сокращение направлений подготовки, на которые есть устойчивый спрос со стороны иностранцев, и, соответственно, снижение динамики роста численности иностранных студентов.

В предыдущих работах авторами были выделены следующие характеристики отношений между организацией и группами заинтересованных сторон (ГЗС): степень желания изменений (являющаяся функцией удовлетворенности и ожиданий в отношении контрагента), степень влияния (на контрагента). Данные характеристики можно представить в виде лингвистических переменных, описываемых с помощью нечетких чисел. В таблице 1 представлено преобразование вербальных оценок степени желания изменений отношений в нечеткие числа.

Таблицуа 1

\section{Преобразование вербальных оценок степени желания изменений отношений в нечеткие числа}

\begin{tabular}{|c|c|c|c|c|c|c|c|c|c|c|c|}
\hline \multirow{2}{*}{$\begin{array}{c}\text { Вербальная оценка степени } \\
\text { желания изменений отношений }\end{array}$} & \multicolumn{10}{|c|}{ Значения $x$} \\
\cline { 2 - 14 } & 0 & 1 & 2 & 3 & 4 & 5 & 6 & 7 & 8 & 9 & 10 \\
\cline { 2 - 14 } & \multicolumn{10}{|c|}{ Значения $\mu(x)$} \\
\hline Отсутствует & 1 & 0,8 & 0,4 & 0,1 & 0 & 0 & 0 & 0 & 0 & 0 & 0 \\
\hline Очень маленькая & 0,8 & 1 & 0,8 & 0,4 & 0,1 & 0 & 0 & 0 & 0 & 0 & 0 \\
\hline Незначительная & 0,4 & 0,8 & 1 & 0,8 & 0,4 & 0,1 & 0 & 0 & 0 & 0 & 0 \\
\hline Небольшая & 0,1 & 0,4 & 0,8 & 1 & 0,8 & 0,4 & 0,1 & 0 & 0 & 0 & 0 \\
\hline Ниже среднего уровня & 0 & 0,1 & 0,4 & 0,8 & 1 & 0,8 & 0,4 & 0,1 & 0 & 0 & 0 \\
\hline Средняя & 0 & 0 & 0,1 & 0,4 & 0,8 & 1 & 0,8 & 0,4 & 0,1 & 0 & 0 \\
\hline Выше среднего уровня & 0 & 0 & 0 & 0,1 & 0,4 & 0,8 & 1 & 0,8 & 0,4 & 0,1 & 0 \\
\hline Большая & 0 & 0 & 0 & 0 & 0,1 & 0,4 & 0,8 & 1 & 0,8 & 0,4 & 0,1 \\
\hline Значительная & 0 & 0 & 0 & 0 & 0 & 0,1 & 0,4 & 0,8 & 1 & 0,8 & 0,4 \\
\hline Очень большая & 0 & 0 & 0 & 0 & 0 & 0 & 0,1 & 0,4 & 0,8 & 1 & 0,8 \\
\hline Абсолютная & 0 & 0 & 0 & 0 & 0 & 0 & 0 & 0,1 & 0,4 & 0,8 & 1 \\
\hline
\end{tabular}

В таблице 2 представлено преобразование вербальных оценок степени взаимного влияния в нечеткие числа. 
Гресько А.А., Солодухин К.С. Выбор смешанных типов стратегий взаимодействия...

Таблица 2

\section{Преобразование вербальных оценок степени взаимного влияния} в нечеткие числа

\begin{tabular}{|c|c|c|c|c|c|c|c|c|c|c|c|}
\hline \multirow{3}{*}{ Вербальная оценка степени взаимного влияния } & \multicolumn{11}{|c|}{ Значения $x$} \\
\hline & -5 & -4 & -3 & -2 & -1 & 0 & 1 & 2 & 3 & 4 & 5 \\
\hline & \multicolumn{11}{|c|}{ Значения $\mu(x)$} \\
\hline $\begin{array}{l}\text { Влияние ГЗС на организацию несравнимо } \\
\text { больше, чем влияние организации на ГЗС } \\
\text { (ВГОНБ) }\end{array}$ & 1 & 1 & 0,4 & 0 & 0 & 0 & 0 & 0 & 0 & 0 & 0 \\
\hline $\begin{array}{l}\text { Влияние ГЗС на организацию существенно } \\
\text { больше, чем влияние организации на ГЗС } \\
\text { (ВГОСБ) }\end{array}$ & 0,4 & 1 & 1 & 0,4 & 0,1 & 0 & 0 & 0 & 0 & 0 & 0 \\
\hline $\begin{array}{l}\text { Влияние ГЗС на организацию умеренно } \\
\text { больше, чем влияние организации на ГЗС } \\
\text { (ВГОУБ) }\end{array}$ & 0 & 0,4 & 1 & 1 & 0,2 & 0 & 0 & 0 & 0 & 0 & 0 \\
\hline $\begin{array}{l}\text { Влияние ГЗС на организацию незначительно } \\
\text { больше, чем влияние организации на ГЗС } \\
\text { (ВГОНЗБ) }\end{array}$ & 0 & 0 & 0,4 & 1 & 1 & 0,4 & 0,1 & 0 & 0 & 0 & 0 \\
\hline $\begin{array}{l}\text { Влияние ГЗС и организации друг на друга } \\
\text { примерно одинаково (ВГОПО) }\end{array}$ & 0 & 0 & 0 & 0,2 & 0,9 & 1 & 0,9 & 0,2 & 0 & 0 & 0 \\
\hline $\begin{array}{l}\text { Влияние организации на ГЗС незначительно } \\
\text { больше, чем влияние ГЗС на организацию } \\
\text { (ВОГНЗБ) }\end{array}$ & 0 & 0 & 0 & 0 & 0,1 & 0,4 & 1 & 1 & 0,4 & 0 & 0 \\
\hline $\begin{array}{l}\text { Влияние организации на ГЗС умеренно } \\
\text { больше, чем влияние ГЗС } \\
\text { на организацию (ВОГУБ) }\end{array}$ & 0 & 0 & 0 & 0 & 0 & 0 & 0,2 & 1 & 1 & 0,4 & 0 \\
\hline $\begin{array}{l}\text { Влияние организации на ГЗС существенно } \\
\text { больше, чем влияние ГЗС на организацию } \\
\text { (ВОГСБ) }\end{array}$ & 0 & 0 & 0 & 0 & 0 & 0 & 0,1 & 0,4 & 1 & 1 & 0,4 \\
\hline $\begin{array}{l}\text { Влияние организации на ГЗС несравнимо } \\
\text { больше, чем влияние ГЗС на организацию } \\
\text { (ВОГНБ) }\end{array}$ & 0 & 0 & 0 & 0 & 0 & 0 & 0 & 0 & 0,4 & 1 & 1 \\
\hline
\end{tabular}

Рассмотрим динамику изменения характеристик отношений между ВГУЭС и ГЗС «Иностранные студенты» по отдельно взятым ресурсам в рамках трех сценариев (табл. 3).

Таблица 3

\section{Динамика изменения характеристик отношений для трех сценариев}

\begin{tabular}{|c|c|c|c|c|c|c|}
\hline \multirow{3}{*}{ Ресурсы } & \multicolumn{6}{|c|}{ Сценарий 1 / Сценарий 2 / Сценарий3 } \\
\hline & \multicolumn{3}{|c|}{ Степень желания изменений отношений } & \multicolumn{3}{|c|}{ Степень взаимного влияния } \\
\hline & 2017 г. & $\begin{array}{c}\text { 2018-2019 } \\
\text { ГГ. }\end{array}$ & $\begin{array}{c}2020-2021 \\
\text { Гг. }\end{array}$ & 2017 г. & $\begin{array}{c}2018- \\
2019 \text { гг. }\end{array}$ & $\begin{array}{c}2020-2021 \\
\text { Гг. }\end{array}$ \\
\hline 1 & 2 & 3 & 4 & 5 & 6 & 7 \\
\hline $\begin{array}{l}\text { Ресурсы, получаемые } \\
\text { иностранными } \\
\text { студентами от вуза }\end{array}$ & & & & & & \\
\hline $\begin{array}{l}\text { Дипломы, } \\
\text { сертификаты }\end{array}$ & $\begin{array}{c}\text { Небольшая / } \\
\text { Небольшая / } \\
\text { Небольшая }\end{array}$ & $\begin{array}{c}\text { Небольшая / } \\
\text { Ниже сред- } \\
\text { него уровня/ } \\
\text { Небольшая }\end{array}$ & $\begin{array}{l}\text { Небольшая / } \\
\text { Средняя / } \\
\text { Небольшая }\end{array}$ & $\begin{array}{l}\text { ВГОПО / } \\
\text { ВГОПО / } \\
\text { ВГОПО }\end{array}$ & $\begin{array}{c}\text { ВГОПО / } \\
\text { ВГОНЗБ / } \\
\text { ВОГНЗБ }\end{array}$ & $\begin{array}{l}\text { ВГОПО / } \\
\text { ВГОУБ / } \\
\text { ВОГНЗБ }\end{array}$ \\
\hline
\end{tabular}


Территория новых возможностей. Вестник ВГУЭС. 2017. № 3

Окончание табл. 3

\begin{tabular}{|c|c|c|c|c|c|c|}
\hline 1 & 2 & 3 & 4 & 5 & 6 & 7 \\
\hline $\begin{array}{l}\text { Технологии } \\
\text { преподавания }\end{array}$ & $\begin{array}{c}\text { Значительная/ } \\
\text { Значительная / } \\
\text { Значительная }\end{array}$ & $\begin{array}{l}\text { Выше сред- } \\
\text { него уровня// } \\
\text { Большая / } \\
\text { Выше сред- } \\
\text { него уровня } \\
\end{array}$ & $\begin{array}{c}\text { Ниже сред- } \\
\text { него уровня/ } \\
\text { Средняя / } \\
\text { Небольшая }\end{array}$ & $\begin{array}{l}\text { ВГОСБ / } \\
\text { ВГОСБ / } \\
\text { ВГОСБ }\end{array}$ & $\begin{array}{l}\text { ВГОУБ / } \\
\text { ВГОСБ / } \\
\text { ВГОНЗБ }\end{array}$ & $\begin{array}{c}\text { ВГОНЗБ / } \\
\text { ВГОСБ / } \\
\text { ВГОПО }\end{array}$ \\
\hline $\begin{array}{l}\text { Возможность } \\
\text { реализации } \\
\text { в культуре и спорте }\end{array}$ & $\begin{array}{c}\text { Небольшая / } \\
\text { Небольшая / } \\
\text { Небольшая }\end{array}$ & $\begin{array}{l}\text { Небольшая/ } \\
\text { Небольшая/ } \\
\text { Небольшая }\end{array}$ & $\begin{array}{c}\text { Небольшая / } \\
\text { Небольшая / } \\
\text { Небольшая }\end{array}$ & $\begin{array}{c}\text { ВОГНЗБ / } \\
\text { ВОГНЗБ / } \\
\text { ВОГНЗБ }\end{array}$ & $\begin{array}{l}\text { ВГОПО / } \\
\text { ВГОПО / } \\
\text { ВГОПО }\end{array}$ & $\begin{array}{l}\text { ВОГНЗБ / } \\
\text { ВОГНЗБ / } \\
\text { ВОГНЗБ }\end{array}$ \\
\hline $\begin{array}{l}\text { Комфортные } \\
\text { условия } \\
\text { проживания }\end{array}$ & $\begin{array}{c}\text { Выше сред- } \\
\text { него уровня/ } \\
\text { Выше сред- } \\
\text { него уровня / } \\
\text { Выше средне- } \\
\text { го уровня } \\
\end{array}$ & $\begin{array}{l}\text { Средняя / } \\
\text { Средняя / } \\
\text { Ниже сред- } \\
\text { него уровня }\end{array}$ & $\begin{array}{c}\text { Ниже сред- } \\
\text { него уровня/ } \\
\text { Средняя / } \\
\text { Небольшая }\end{array}$ & $\begin{array}{l}\text { ВГОУБ / } \\
\text { ВГОУБ / } \\
\text { ВГОУБ }\end{array}$ & $\begin{array}{l}\text { ВГОУБ / } \\
\text { ВГОУБ / } \\
\text { ВГОНЗБ }\end{array}$ & $\begin{array}{c}\text { ВГОНЗБ } \\
\text { / ВГОУБ / } \\
\text { ВГОПО }\end{array}$ \\
\hline Система адаптации & $\begin{array}{c}\text { Незначитель- } \\
\text { ная/ Незначи- } \\
\text { тельная/ Не- } \\
\text { значительная / }\end{array}$ & $\begin{array}{c}\text { Незначи- } \\
\text { тельная / } \\
\text { Незначи- } \\
\text { тельная / } \\
\text { Очень ма- } \\
\text { ленькая }\end{array}$ & $\begin{array}{c}\text { Очень ма- } \\
\text { ленькая / } \\
\text { Небольшая/ } \\
\text { Очень ма- } \\
\text { ленькая }\end{array}$ & $\begin{array}{c}\text { ВГОПО / } \\
\text { ВГОПО / } \\
\text { ВГОПО }\end{array}$ & $\begin{array}{l}\text { ВГОПО / } \\
\text { ВГОПО / } \\
\text { ВОГНЗБ }\end{array}$ & $\begin{array}{l}\text { ВОГНЗБ / } \\
\text { ВГОПО / } \\
\text { ВОГНЗБ }\end{array}$ \\
\hline $\begin{array}{l}\text { Коммуникативная } \\
\text { площадка }\end{array}$ & $\begin{array}{l}\text { Средняя / } \\
\text { Средняя / } \\
\text { Средняя }\end{array}$ & $\begin{array}{c}\text { Ниже } \\
\text { среднего } \\
\text { уровня / } \\
\text { Небольшая/ } \\
\text { Средняя } \\
\end{array}$ & $\begin{array}{c}\text { Небольшая/ } \\
\text { Незначи- } \\
\text { тельная / } \\
\text { Выше сред- } \\
\text { него уровня }\end{array}$ & $\begin{array}{c}\text { ВГОПО / } \\
\text { ВГОПО / } \\
\text { ВГОПО }\end{array}$ & $\begin{array}{l}\text { ВОГНЗБ / } \\
\text { ВОГНЗБ / } \\
\text { ВГОНЗБ }\end{array}$ & $\begin{array}{c}\text { ВОГУБ / } \\
\text { ВОГУБ / } \\
\text { ВГОУБ }\end{array}$ \\
\hline \multicolumn{7}{|l|}{$\begin{array}{l}\text { Ресурсы, } \\
\text { получаемые вузом } \\
\text { от иностранных } \\
\text { студентов }\end{array}$} \\
\hline $\begin{array}{l}\text { Оплата } \\
\text { образовательных } \\
\text { услуг }\end{array}$ & $\begin{array}{l}\text { Средняя / } \\
\text { Средняя / } \\
\text { Средняя }\end{array}$ & \begin{tabular}{|c} 
Средняя / \\
Средняя / \\
Выше сред- \\
него уровня
\end{tabular} & $\begin{array}{c}\text { Средняя / } \\
\text { Ниже сред- } \\
\text { него уровня / } \\
\text { Большая }\end{array}$ & $\begin{array}{c}\text { ВОГНЗБ / } \\
\text { ВОГНЗБ / } \\
\text { ВОГНЗБ }\end{array}$ & $\begin{array}{l}\text { ВОГУБ / } \\
\text { ВОГУБ / } \\
\text { ВОГНЗБ }\end{array}$ & $\begin{array}{c}\text { ВОГУБ / } \\
\text { ВОГУБ / } \\
\text { ВГОПО }\end{array}$ \\
\hline Имидж & $\begin{array}{l}\text { Средняя / } \\
\text { Средняя / } \\
\text { Средняя }\end{array}$ & $\begin{array}{c}\text { Ниже сред- } \\
\text { него уровня/ } \\
\text { Ниже сред- } \\
\text { него уровня } \\
\text { / Средняя }\end{array}$ & $\begin{array}{l}\text { Небольшая / } \\
\text { Небольшая / } \\
\text { Средняя }\end{array}$ & $\begin{array}{l}\text { ВГОСБ / } \\
\text { ВГОСБ / } \\
\text { ВГОСБ }\end{array}$ & $\begin{array}{l}\text { ВГОСБ / } \\
\text { ВГОУБ / } \\
\text { ВГОСБ }\end{array}$ & $\begin{array}{c}\text { ВГОУБ / } \\
\text { ВГОУБ / } \\
\text { ВГОСБ }\end{array}$ \\
\hline $\begin{array}{l}\text { Выполнение } \\
\text { показателей } \\
\text { мониторинга }\end{array}$ & $\begin{array}{c}\text { Незначитель- } \\
\text { ная / Незначи- } \\
\text { тельная / Не- } \\
\text { значительная }\end{array}$ & $\begin{array}{l}\text { Очень ма- } \\
\text { ленькая / } \\
\text { Очень ма- } \\
\text { ленькая / } \\
\text { Незначи- } \\
\text { тельная }\end{array}$ & $\begin{array}{c}\text { Очень ма- } \\
\text { ленькая / } \\
\text { Отсутствует / } \\
\text { Небольшая }\end{array}$ & $\begin{array}{l}\text { ВГОУБ / } \\
\text { ВГОУБ / } \\
\text { ВГОУБ }\end{array}$ & $\begin{array}{l}\text { ВГОУБ / } \\
\text { ВОГНЗБ / } \\
\text { ВГОУБ }\end{array}$ & $\begin{array}{c}\text { ВОГНЗБ / } \\
\text { ВОГНЗБ / } \\
\text { ВГОУБ }\end{array}$ \\
\hline
\end{tabular}

Как уже отмечалось в предыдущих работах, для каждой группы стейкхолдеров на основе анализа характеристик отношений может быть выбран определенный (наиболее подходящий при прочих равных) тип стратегии взаимодействия: удовлетворение запросов, защита, воздействие, сотрудничество, сдержанность.

Для того чтобы определить, какой тип стратегии следует применять к стейкхолдеру в сложившейся ситуации, каждому из типов ставится в соответствие 
нечеткий весовой коэффициент, отражающий целесообразность применения стратегии данного типа. Целесообразность применения стратегии $l$-го типа $(l=\overline{1,5})$ в отношении $k$-й ГЗС $\left(w_{l}^{k}\right)$ рассчитывается по следующим формулам:

$w_{1}^{k}=\frac{5+G_{1}^{k}-V^{k}}{20}, w_{2}^{k}=\frac{10-\left|G_{1}^{k}-5\right|-V^{k}}{15}, w_{3}^{k}=\frac{5+G_{2}^{k}+V^{k}}{20}, w_{4}^{k}=\frac{25-G_{1}^{k}-G_{2}^{k}-\left|V^{k}\right|}{25}, w_{5}^{k}=\frac{10-\left|G_{2}^{k}-5\right|+V^{k}}{15}$,

где $V^{k}$ - степень взаимного влияния организации и $k$-й ГЗС, $G_{1}^{k}-$ степень желания изменений $k$-й ГЗС в отношении организации, $G_{2}^{k}-$ степень желания изменений организации в отношении $k$-й ГЗС.

Пусть имеется $d$ сценариев изменения внешней среды, в результате которых в каждом из $t$ периодов некоторым образом изменяются отношения организации с $k$-й ГЗС. На основе полученных оценок характеристик отношений рассчитываются коэффициенты целесообразности применения $l$-го типа стратегии в отношении $k$-й ГЗС $\left(w_{l i j}^{k}\right)$ в рамках $i$-го сценария $(i=\overline{1, d})$. Коэффициенты целесообразности применения $l$-го типа стратегии в отношении $k$-ой ГЗС по каждому сценарию сводятся к одному интегральному коэффициенту $\left(w_{l i}^{k}\right)$ :

$$
w_{l i}^{k}=\frac{\sum_{j=1}^{t} w_{l i j}^{k} \cdot q_{i j}^{k}}{\sum_{j=1}^{t} q_{i j}^{k}},
$$

где $t$ - количество периодов, $i$ - номер сценария, $q_{i j}^{k}$ - коэффициент, отражающий степень уверенности эксперта (или лица принимающего решение (ЛПР)) в полученном для $j$-го периода коэффициенте целесообразности применения $l$-го типа стратегии в отношении $k$-й $Г$ З в рамках $i$-го сценария.

Расчет интегральных коэффициентов целесообразности применения типов стратегий производится с использованием нечетко-множественных операций [7; 13].

Вначале рассчитываются нечеткие «идеальные» значения целесообразности применения стратегий: $w_{1}^{u k}, w_{2}^{u k}, w_{3}^{u k}, w_{4}^{u k}, w_{5}^{u k}$. Для этого выбираются нечеткие характеристики отношений, при которых весовые коэффициенты целесообразности применения типов стратегий достигают своих максимальных значений (в соответствии с выбранными лингвистическими шкалами).

Затем на основе реальных оценок характеристик отношений рассчитываются «реальные» нечеткие значения целесообразности применения стратегий: $w_{1}^{p k}, w_{2}^{p k}, w_{3}^{p k}, w_{4}^{p k}, w_{5}^{p k}$.

На последнем этапе для каждого типа стратегии определяется расстояние Хемминга между «идеальным» и «реальным» значением целесообразности применения стратегии по следующей формуле:

$$
\rho\left(w_{l i}^{u k}, w_{l i}^{p k}\right)=\int_{-\infty}^{+\infty}\left|\mu_{w_{l i}^{u k}}\left(x_{h}\right)-\mu_{w_{l i}^{p k}}\left(x_{h}\right)\right| d x,
$$

где $\mu_{w_{l i}^{u k}}\left(x_{h}\right)$ и $\mu_{w_{l i}^{p k}}\left(x_{h}\right)$ - функции принадлежности соответственно «идеальной» и «реальной» целесообразности применения типов стратегий.

Выбор следует осуществлять в пользу того типа стратегии, которому будет соответствовать наименьшее расстояние Хемминга между «идеальной» и «реальной» целесообразностью применения стратегии. 
В рассмотренном нами примере расстояния Хемминга были рассчитаны для интегральных весовых коэффициентов целесообразности применения типов стратегий по трем сценариям (табл. 4-6).

Таблицุа 4

\section{Расстояния Хемминга для типов стратегий взаимодействия для трех сщенариев}

\begin{tabular}{|l|c|c|c|c|c|}
\hline \multirow{2}{*}{$\begin{array}{c}\text { Сценарии } \\
\text { (вероятность) }\end{array}$} & \multicolumn{5}{|c|}{ Типы стратегий взаимодействия } \\
\cline { 2 - 6 } & $\begin{array}{c}\text { Удовлетворение } \\
\text { запросов }\end{array}$ & Защита & Воздействие & Сотрудничество & $\begin{array}{c}\text { Сдержан- } \\
\text { ность }\end{array}$ \\
\hline Сценарий 1 (средняя) & 0,89 & 0,64 & 1,1 & 0,91 & 1 \\
\hline $\begin{array}{l}\text { Сценарий 2 (ниже } \\
\text { среднего уровня) }\end{array}$ & 0,86 & 0,54 & 0,98 & 0,86 & 0,87 \\
\hline Сценарий 3 (низкая) & 0,83 & 0,6 & 0,99 & 0,95 & 1,01 \\
\hline $\begin{array}{l}\text { Математическое } \\
\text { ожидание }\end{array}$ & 0,868 & 0,599 & 1,039 & 0,901 & 0,959 \\
\hline $\begin{array}{l}\text { Среднеквадратичное } \\
\text { отклонение }\end{array}$ & 0,0229 & 0,0442 & 0,0582 & 0,0324 & 0,0625 \\
\hline
\end{tabular}

Как уже отмечалось, может возникнуть ситуация, при которой в отношении одного и того же стейкхолдера по разным наборам ресурсов организации следует придерживаться стратегий разных типов. Тем самым появляется необходимость формирования смешанных стратегий из стратегий базовых типов. В результате возникают так называемые «физические смеси стратегий» [14]. Поэтому расчет расстояний Хемминга лучше делать не в целом для группы, а по отдельному ресурсу.

В нашем случае необходимо определить доли (веса) ресурсных компонентов, для которых наиболее целесообразно применение той или иной стратегии, и затем использовать метод формирования стратегий смешанного типа.

В подобных задачах исходом для принимающего решение при выборе им альтернативы $s=\overline{1, r}$ является случайная величина вида $\xi_{s}=\left[\begin{array}{lll}a_{s}^{1} & \ldots & a_{s}^{m} \\ p_{1} & \ldots & p_{m}\end{array}\right]$, где $\left(\begin{array}{lll}a_{s}^{1} & \ldots & a_{s}^{m}\end{array}\right)$ - вектор выигрышей; $\left(\begin{array}{lll}p_{1} & \ldots & p_{m}\end{array}\right)$ - вектор вероятностей выигрышей. Если принимающий решение использует смешанную стратегию $x=\left(x_{1}, \ldots, x_{r}\right)$, то исходом, соответствующим этой смешанной стратегии, будет случайная величина $\xi=\sum_{s=1}^{r} x_{s} \xi_{s}$.

Математическое ожидание данной случайной величины может быть найдено по формуле:

$$
M \xi=M\left(\sum_{s=1}^{r} x_{s} \xi_{s}\right)=\sum_{s=1}^{r} M \xi_{s}=\sum_{s=1}^{r} x_{s} M_{s}
$$

Для отклонения случайной величины $\xi$ от ее ожидаемого значения выполняется условие $\xi-M \xi=\sum_{s=1}^{r} x_{s} \xi_{s}-\sum_{s=1}^{r} x_{s} M_{s}=\sum_{s=1}^{r} x_{s}\left(\xi_{s}-M_{s}\right)$, откуда получаем выражение для дисперсии:

$D \xi=M(\xi-M \xi)^{2}=M\left[\left(\sum_{s=1}^{r} x_{s}\left(\xi_{s}-M_{S}\right)\right)\left(\sum_{z=1}^{r} x_{z}\left(\xi_{z}-M_{z}\right)\right)\right]=\sum_{\mathrm{s}, \mathrm{Z}=1}^{\mathrm{r}} \mathrm{x}_{\mathrm{s}} \mathrm{x}_{\mathrm{Z}} \mathrm{M}\left[\left(\xi_{\mathrm{s}}-(5)\right.\right.$
$\left.\left.\mathrm{M}_{\mathrm{s}}\right)\left(\xi_{\mathrm{z}}-\mathrm{M}_{\mathrm{z}}\right)\right]$. 
Гресько А.А., Солодухин К.С. Выбор смешанных типов стратегий взаимодействия...

В данном случае риск применения стратегий смешанного типа будет меньше по сравнению с риском использования «чистых» стратегий.

По каждой ресурсной компоненте, участвующей в ресурсном обмене университета и его группы стейкхолдеров, для каждого из трех сценариев нами были рассчитаны расстояния Хемминга для всех типов стратегий взаимодействия. В таблицах 5 и 6 приведены математические ожидания расстояний Хемминга (с учетом четких вероятностей сценариев, полученных из заданных нечетких (см. [13]).

Таблицьа 5

\section{Расстояния Хемминга для ресурсов, получаемых университетом от иностранных студентов}

\begin{tabular}{|l|c|c|c|}
\hline \multirow{2}{*}{$\begin{array}{c}\text { Ресурсы, получаемые университетом } \\
\text { от иностранных студентов }\end{array}$} & \multirow{2}{*}{$\begin{array}{c}\text { Важность } \\
\text { ресурса }\end{array}$} & \multicolumn{2}{|c|}{ Тип стратегии } \\
\cline { 4 - 5 } Оплата образовательных услуг & Воздействие & Сдержанность \\
\hline Имидж & $\begin{array}{c}\text { Вышеднего } \\
\text { уровня }\end{array}$ & 0,69 & 0,41 \\
\hline Выполнение показателей мониторинга & $\begin{array}{c}\text { Выше среднего } \\
\text { уровня }\end{array}$ & 1,09 & 1,13 \\
\hline
\end{tabular}

Расстояния Хемминга для ресурсов, получаемых иностранными Таблицьа 6 студентами от университета

\begin{tabular}{|l|c|c|c|}
\hline \multirow{2}{*}{$\begin{array}{c}\text { Ресурсы, получаемые иностранными } \\
\text { студентами от университета }\end{array}$} & \multirow{2}{*}{$\begin{array}{c}\text { Важность } \\
\text { ресурса }\end{array}$} & $\begin{array}{c}\text { Удовлетворение } \\
\text { запросов }\end{array}$ & Защита \\
\hline Дипломы, сертификаты & Высокая & 0,87 & 0,5 \\
\hline Технологии преподавания & Высокая & 0,44 & 0,57 \\
\hline $\begin{array}{l}\text { Возможность реализации в культуре } \\
\text { и спорте }\end{array}$ & Средняя & 1,03 & 0,63 \\
\hline Комфортные условия проживания & $\begin{array}{c}\text { Выше среднего } \\
\text { уровня }\end{array}$ & 0,65 & 0,49 \\
\hline Система адаптации & Очень высокая & 1,06 & 0,69 \\
\hline Коммуникативная площадка & Высокая & 0,92 & 0,65 \\
\hline
\end{tabular}

Нетрудно сделать вывод (табл. 5), что по ресурсам «Оплата образовательных услуг» и «Выполнение показателей мониторинга эффективности деятельности» целесообразнее придерживаться стратегии сдержанности. Относительно ресурса «Имидж» лучше придерживаться стратегии воздействия. Для того чтобы задать вероятностный вектор смешанной стратегии, нечеткие оценки важности ресурсов нормируются с последующей дефазификацией [13]. В данном случае получился следующий вероятностный вектор смешанной стратегии $(0,29 ; 0,71)$. Рассчитывая для данной смешанной стратегии математическое ожидание и среднеквадратичное отклонение, получаем: $M=0,98, \sigma=0,057$. Значение математического ожидания оказалось больше, чем при чистом типе стратегии сдержанности (который мы, очевидно, выбрали бы, если ограничивались только чистыми стратегиями), но существенно меньше, чем при чистом типе стратегии воздействия (табл. 5). 
При этом показатель риска («Среднеквадратичное отклонение») оказался меньше по сравнению с обоими типами стратегий.

По ресурсу «Технологии преподавания» целесообразнее придерживаться стратегии удовлетворения запросов, так как у данного типа стратегии расстояние Хемминга меньше, по сравнению со стратегией защиты (табл. 6). По всем остальным ресурсам следует придерживаться стратегии защиты. Для данного смешанного типа стратегии был получен вероятностный вектор $(0,11 ; 0,89)$. Рассчитывая для данной смешанной стратегии математическое ожидание и среднеквадратичное отклонение, получаем: $M=0,629, \sigma=0,04$. Значение математического ожидания оказалось немного хуже, чем при чистом типе стратегии защиты, но намного лучше, чем при чистом типе стратегии удовлетворения запросов. Значение риска («Среднеквадратичное отклонение») изменилось в лучшую сторону, но очень незначительно (что и следовало ожидать при таком вероятностном векторе).

Полученные результаты свидетельствуют о том, что ВГУЭС удалось выстроить систему взаимодействия с иностранными студентами, позволяющую в целом удовлетворять запросы учащихся на высоком уровне и формирующую у них позитивные ожидания. При этом «узким» местом являются технологии преподавания, совершенствованию которых необходимо уделить особое внимание. Это должно привести и к улучшению имиджа вуза, также требующего повышенного внимания.

1. Ватолкина Н.Ш., Федоткина О.П. Академическая мобильность студентов в условиях интернационализации образования // Университетское управление: практика и анализ. 2015. №2(96). С. 17-26.

2. Горбунова М.В., Гресько А.А., Солодухин К.С. Динамическая модель выбора смешанных типов стратегий взаимодействия организации с группами стейкхолдеров // Фундаментальные исследования. 2015. № 2-25. С. 5626-5630.

3. Горбунова М.В., Гресько А.А., Солодухин К.С. Многопериодная модель выбора смешанных типов стратегий взаимодействия вуза со стейкхолдерами // Проблемы современной экономики. 2016. №3. С. 215-218.

4. Гресько А.А., Солодухин К.С., Чен А.Я. Многопериодная модель ресурсного взаимодействия заинтересованных сторон вуза // Азимут научных исследований: экономика и управление. 2016. Т. 5, № 2 (15). С. 77-81.

5. Гресько А.А., Солодухин К.С. Многопериодные модели выбора стратегий взаимодействия вуза со стейкхолдерами в условиях риска // Университетское управление: практика и анализ. 2014. № 4-5. С. 36-43.

6. Гурков И.Б. Условия устойчивого развития коммерческой фирмы // Экономическая наука современной России. 2011. №3. С. 100-114.

7. Заде Л.А. Понятие лингвистической переменной и его применение к принятию приближенных решений. М.: Мир, 1976.

8. Иностранные студенты приезжают во ВГУЭС за качественным образованием. URL: http://www.vvsu.ru/latest/article/10776096. 
9. Князев Е.А., Дрантусова Н.В. Дифференциация в высшем образовании: основные концепции и подходы к изучению // Университетское управление: практика и анализ. 2012. №5. С. 43-52.

10. Козулина А.П. Современные проблемы подготовки иностранных студентов к обучению в российских вузах // Современные проблемы науки и образования. 2014. №5. C. 141.

11. Малышева Л.А. Стратегическое управление в вузах: технологии и инструменты // Университетское управление: практика и анализ. 2013. № 1. С. 78-87.

12. Погукаева А.В., Коберник Л.Н., Омельянчук Е.Л. Адаптация иностранных студентов в российском вузе // Современные проблемы науки и образования. 2016. № 3. С. 294.

13. Птускин А.С. Нечеткие модели задач принятия стратегических решений на предприятиях: ди. ... Д-ра экон. наук: 08.00.13. М., 2004.

14. Розен В.В. Математические модели принятия решений в экономике: учеб. пособие. М.: Книжный дом «Университет», Высшая школа, 2002. 288 с.

15. Солодухин К.С. Стратегическое управление вузом как стейкхолдер-компанией. СПб.: Изд-во Политехн. ун-та, 2009. 289 с.

\section{Транслитерация}

1. Vatolkina N.Sh., Fedotkina O.P. Akademicheskaya mobil'nost' studentov v usloviyakh internatsionalizatsii obrazovaniya, Universitetskoe upravlenie: praktika i analiz, 2015, No 2 (96), pp. 17-26.

2. Gorbunova M.V., Gres'ko A.A., Solodukhin K.S. Dinamicheskaya model' vybora smeshannykh tipov strategii vzaimodeistviya organizatsii s gruppami steikkholderov, Fundamental'nye issledovaniya, 2015, No 2-25, pp. 5626-5630.

3. Gorbunova M.V., Gres'ko A.A., Solodukhin K.S. Mnogoperiodnaya model' vybora smeshannykh tipov strategii vzaimodeistviya vuza so steikkholderami, Problemy sovremennoi ekonomiki, 2016, No 3, pp. 215-218.

4. Gres'ko A.A., Solodukhin K.S., Chen A.Ya. Mnogoperiodnaya model' resursnogo vzaimodeistviya zainteresovannykh storon vuza, Azimut nauchnykh issledovanii: ekonomika i upravlenie, 2016, vol. 5, No 2(15), pp. 77-81.

5. Gres'ko A.A., Solodukhin K.S. Mnogoperiodnye modeli vybora strategii vzaimodeistviya vuza so steikkholderami v usloviyakh riska, Universitetskoe upravlenie: praktika i analiz, 2014, No 4-5, pp. 36-43.

6. Gurkov I.B. Usloviya ustoichivogo razvitiya kommercheskoi firmy, Ekonomicheskaya nauka sovremennoi Rossii, 2011, No 3, pp. 100-114.

7. Zade L.A. Ponyatie lingvisticheskoi peremennoi i ego primenenie k prinyatiyu priblizhennykh reshenii, M.: Mir, 1976.

8. Inostrannye studenty priezzhayut vo VGUES za kachestvennym obrazovaniem. URL: http://www.vvsu.ru/latest/article/10776096.

9. Knyazev E.A., Drantusova N.V. Differentsiatsiya v vysshem obrazovanii: osnovnye kontseptsii i podkhody k izucheniyu, Universitetskoe upravlenie: praktika i analiz, 2012, No 5, pp. 43-52. 
10. Kozulina A.P. Sovremennye problemy podgotovki inostrannykh studentov k obucheniyu v rossiiskikh vuzakh, Sovremennye problemy nauki i obrazovaniya, 2014, No 5, p. 141.

11. Malysheva L.A. Strategicheskoe upravlenie v vuzakh: tekhnologii i instrumenty, Universitetskoe upravlenie: praktika i analiz, 2013, No 1, pp. 78-87.

12. Pogukaeva A.V., Kobernik L.N., Omel'yanchuk E.L. Adaptatsiya inostrannykh studentov v rossiiskom vuze, Sovremennye problemy nauki i obrazovaniya, 2016, No 3, p. 294.

13. Ptuskin A.S. Nechetkie modeli zadach prinyatiya strategicheskikh reshenii na predpriyatiyakh: dis... d-ra ekon. nauk: 08.00.13. Moskva, 2004.

14. Rozen V.V. Matematicheskie modeli prinyatiya reshenii v ekonomike: ucheb. posobie. M.: Knizhnyi dom «Universitet», Vysshaya shkola, 2002, 288 p.

15. Solodukhin K.S. Strategicheskoe upravlenie vuzom kak steikkholder-kompaniei. SPb.: Izd-vo Politekhn. un-ta, 2009. 289 p.

(C) А.А. Гресько, 2017

(C) К.С. Солодухин, 2017

Для цитирования: Гресько А.А., Солодухин К.С. Выбор смешанных типов стратегий взаимодействия университета с иностранными студентами на основе нечеткой многопериодной модели // Вестник Владивостокского государственного университета экономики и сервиса. 2017. T. 9, № 3. С. 164-178.

For citation: Gresko A.A., Solodukhin K.S. Selecting mixed types of university engagement strategies with foreign student based on fuzzy multi-period model, The Territory of New Opportunities. The Herald of Vladivostok State University of Economics and Service, 2017, Vol. 9, No 1, pp. 164-178.

DOI dx.doi.org/10.24866/VVSU/2073-3984/2017-3/164-178

Дата поступления: 08.08.2017. 